\title{
Shear Deformation of Steel Fiber-Reinforced Prestressed Concrete Beams
}

\author{
Jin-Ha Hwang ${ }^{1)}$, Deuck Hang Lee ${ }^{2)}$, Hyunjin Ju'), Kang Su Kim ${ }^{1), *}$, Thomas H.-K. Kang ${ }^{3)}$, and \\ Zuanfeng Pan ${ }^{4}$
}

(Received March 21, 2016, Accepted June 20, 2016, Published online July 14, 2016)

\begin{abstract}
Steel fiber-reinforced prestressed concrete (SFRPSC) members typically have high shear strength and deformation capability, compared to conventional prestressed concrete (PSC) members, due to the resistance provided by steel fibers at the crack surface after the onset of diagonal cracking. In this study, shear tests were conducted on the SFRPSC members with the test variables of concrete compressive strength, fiber volume fraction, and prestressing force level. Their localized behavior around the critical shear cracks was measured by a non-contact image-based displacement measurement system, and thus their shear deformation was thoroughly investigated. The tested SFRPSC members showed higher shear strengths as the concrete compressive strength or the level of prestress increased, and their stiffnesses did not change significantly, even after diagonal cracking due to the resistance of steel fibers. As the level of prestress increased, the shear deformation was contributed by the crack opening displacement more than the slip displacement. In addition, the local displacements around the shear crack progressed toward directions that differ from those expected by the principal strain angles that can be typically obtained from the average strains of the concrete element. Thus, this localized deformation characteristics around the shear cracks should be considered when measuring the local deformation of concrete elements near discrete cracks or when calculating the local stresses.
\end{abstract}

Keywords: SFRPSC, shear, prestressed concrete, steel fiber, shear deformation, shear strength.

\section{Introduction}

It is generally known that prestressed concrete (PSC) members without transverse reinforcement have brittle failure modes in shear with a rapid load decrease after diagonal cracking (Hawkins and Ghosh 2006; Avendaño and Bayrak 2011; Padmarajaiah and Ramaswamy 2001). On the other hand, steel fiber-reinforced prestressed concrete (SFRPSC) members have higher shear strength and deformation capability compared to conventional PSC members because of the resistance of steel fibers at the crack surface after diagonal cracking (Narayanan and Darwish 1987; Batson et al. 1972; Tan et al. 1996; Padmarajaiah and Ramaswamy 2004;

\footnotetext{
${ }^{1)}$ Department of Architectural Engineering, University of Seoul, Seoul 02504, Korea.

*Corresponding Author; E-mail: kangkim@uos.ac.kr

${ }^{2)}$ Department of Civil and Environmental Engineering, University of Illinois at Urbana-Champaign, Urbana, IL 61801, USA.

${ }^{3)}$ Department of Architecture \& Architectural Engineering, Seoul National University, Seoul 08826, Korea.

${ }^{4)}$ Department of Building Engineering, Tongji University, Shanghai 200092, People's Republic of China.

Copyright $($ The Author(s) 2016. This article is published with open access at Springerlink.com
}

Furlan and Hanai 1999; Hwang et al. 2015; Thomas and Ramaswamy 2006; Liu et al. 2009; Tadepalli et al. 2011; Campione 2014; Colajanni et al. 2012; Dinh et al. 2010; Spinella et al. 2012; Tadepalli et al. 2015; Islam and Alam 2013; Karl et al. 2011). The shear behavior of the SFRPSC members results from very complex mechanisms, and the local behavior at the crack surface of SFRPSC beams is very difficult to understand. In recent studies (Tan et al. 1996; Hwang et al. 2015; Vecchio and Collins 1986; Watanabe and Lee 1998), the smeared models that take into account the average strain and local behavior at the crack surface have shown great advances, while few studies have been performed with detailed measurements and analysis on the local behavior of discrete cracks. In this study, in order to better understand the shear behavior of SFRPSC beams by looking into both the global and local behavior, shear tests were conducted using SFRPSC members with the primary test variables of concrete compressive strength, fiber volume fraction, and prestress level. The local behavior around the cracks of the specimens was measured using a non-contact image-based displacement measurement system. The local behavior was then analyzed along with the shear behavior.

\section{Experimental Program}

In this study, a total of five SFRPSC beam specimens were manufactured and tested as summarized in Table 1. The 
specimens were named according to the concrete compressive strength $(\mathrm{H}$ or $\mathrm{N})$, prestressing force level (P0, $\mathrm{P} 1$, or $\mathrm{P} 2)$, and fiber volume fraction (F0 or F1). As shown in Fig. 1a, the specimens had a T-shaped cross-section, and were $300 \mathrm{~mm}$ in height and $100 \mathrm{~mm}$ in web width. For all specimens, eight deformed bars with a diameter of $13 \mathrm{~mm}$ (D13) were placed in the concrete flange, and two deformed bars with a diameter of $22 \mathrm{~mm}$ (D22) were placed on the tension side. In addition to the tension reinforcement, one and two strands with a diameter of $12.7 \mathrm{~mm}$ were placed in the P1 and P2 specimens, respectively, while the HP0F1 specimen, which was not prestressed, was reinforced with a D13 bar that had a cross-sectional area similar to the $12.7 \mathrm{~mm}$ diameter strand. As shown in Fig. 1b, D10 stirrups with two legs were placed on the right side of the specimens at spacings of $130 \mathrm{~mm}$ to induce shear failure only on the left side. Two-point loads were applied on the specimens with a clear span of $2100 \mathrm{~mm}$ and a shear span of $750 \mathrm{~mm}$. As shown in Table 1, the jacking forces $\left(P_{p j}\right)$ applied to the $\mathrm{P} 1$ and P2 series specimens were 132.3 and $232.2 \mathrm{kN}$, respectively, and their effective prestressing forces $\left(P_{e}\right)$ measured by strain gauges installed on the strands were about 128 and $218 \mathrm{kN}$ on average, respectively. The concrete compressive strengths ranged from 57.1 to $67.8 \mathrm{MPa}$ in the $\mathrm{H}$ series specimens and from 42.6 to $43.8 \mathrm{MPa}$ in the $\mathrm{N}$ series specimens. SD400 steel reinforcements were used for the reinforcing bars, and $1860 \mathrm{MPa}$ low-relaxation strands were used for the prestressing strands. Hooked steel fibers of $30 \mathrm{~mm}$ in length, $0.5 \mathrm{~mm}$ in diameter, and a yield strength of $981 \mathrm{MPa}$ were used, and the fiber volume fraction of all specimens was $1.5 \%$.

As shown in Fig. 2, targets were installed between the loading point and the support at intervals of $50 \mathrm{~mm}$ in the vertical and horizontal directions, and the three-dimensional coordinates of each target were measured by an image-based displacement measurement system. Using this system, the relative displacements between any two targets can be measured, and therefore the amount of deformation and strain could be obtained at all locations on the side of the beam. In this study, the crack opening and slip behavior around critical cracks as well as the average shear strains in the entire shear span of the specimens were analyzed.

\section{Test Results}

\subsection{Load-Deflection}

Figure 3 shows the load-displacement relationship of the specimens with the marks on the diagonal cracking load $\left(V_{c d r}\right)$ and the ultimate load $\left(V_{\max }\right)$, while Fig. 4 shows the
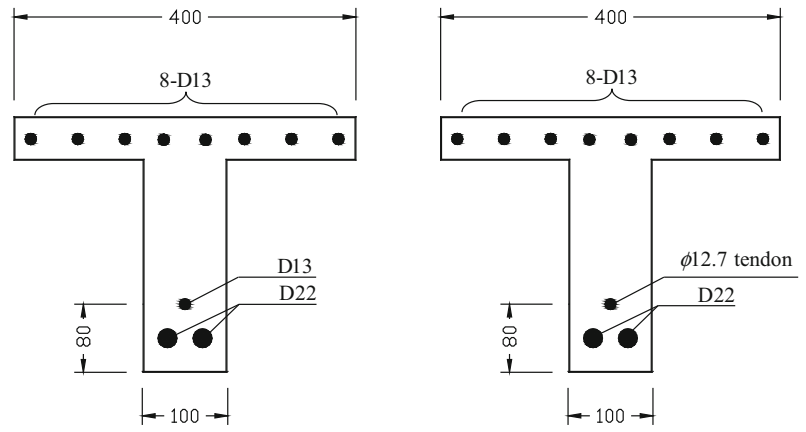

(a)

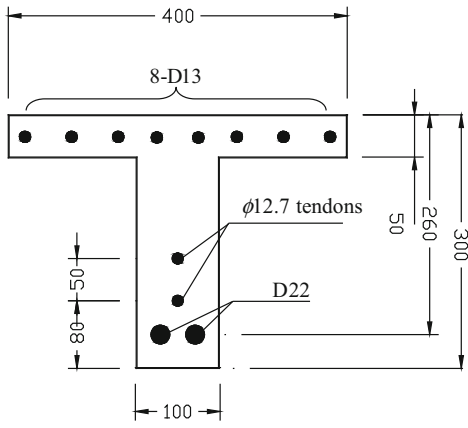

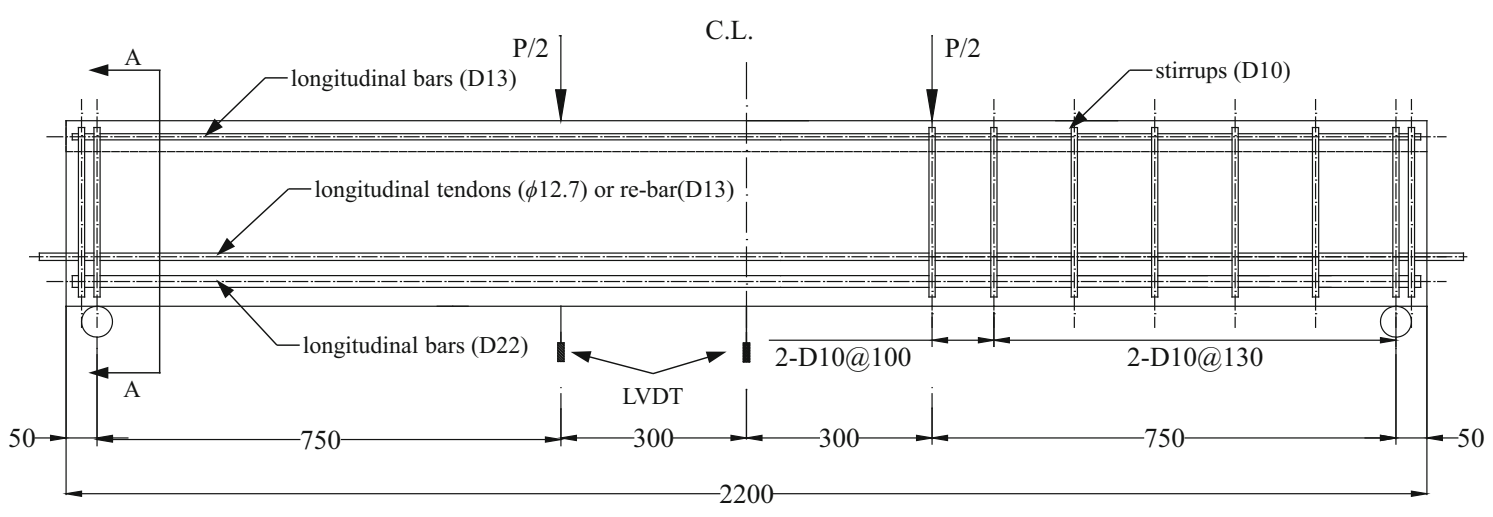

(b)

Fig. 1 Section properties and specimen details (unit: $\mathrm{mm}$ ). a Cross section properties (specimens P0, P1, P2 from the left), b specimen details. 
Table 1 Summary of test specimens.

\begin{tabular}{c|c|c|c|c|c|c|c}
\hline Specimen name & $P_{p j}(\mathrm{kN})$ & $P_{e}(\mathrm{kN})$ & $f_{p c}(\mathrm{MPa})$ & $\rho_{s}(\%)$ & $\rho_{p}(\%)$ & $f_{c}^{\prime}(\mathrm{MPa})$ & $V_{f}(\%)$ \\
\hline \hline NP1F0 & 132.3 & 127.6 & 2.84 & 2.98 & 0.38 & 43.8 & - \\
\hline HP0F1 & - & - & - & 3.46 & - & 67.8 & 1.5 \\
\hline HP1F1 & 132.3 & 129.0 & 2.87 & 2.98 & 0.38 & 65.4 & 1.5 \\
\hline NP2F1 & 232.2 & 214.7 & 4.77 & 2.98 & 0.76 & 42.6 & 1.5 \\
\hline HP2F1 & 232.2 & 220.6 & 4.9 & 2.98 & 0.76 & 57.1 & 1.5 \\
\hline
\end{tabular}

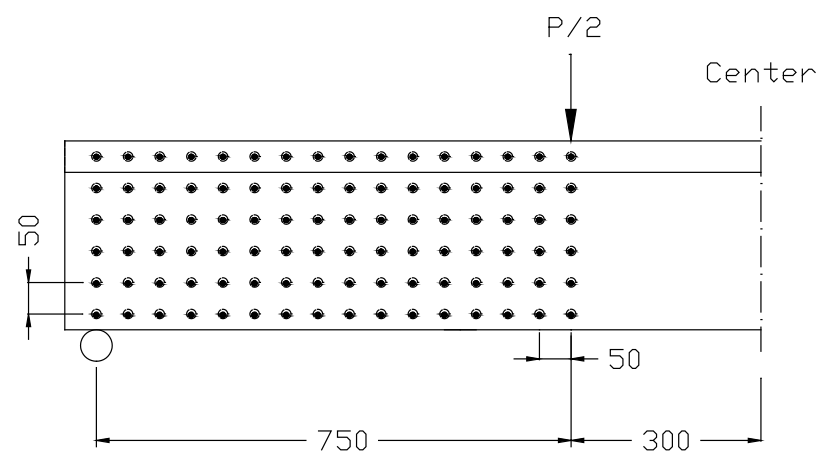

(a)

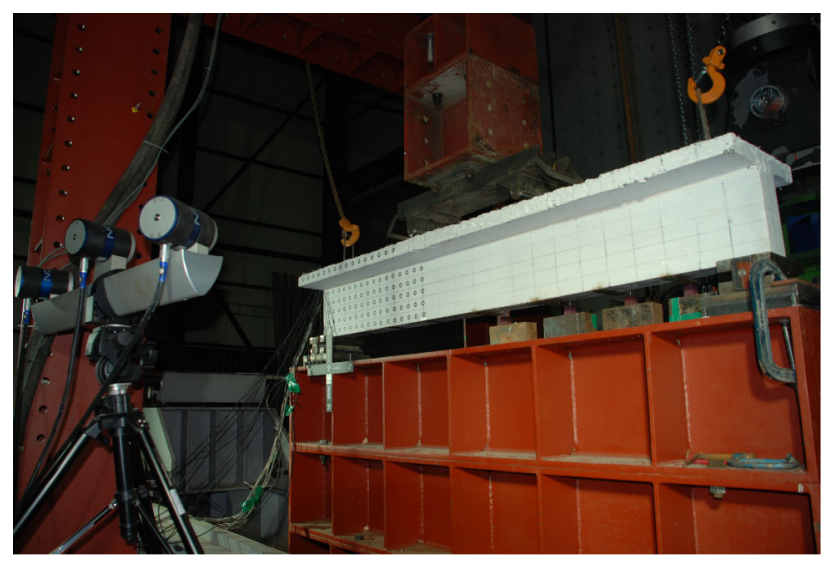

(b)

Fig. 2 Image-based displacement measurement system. a Targets for measuring displacements (unit: $\mathrm{mm}$ ), b measurement equipment.

crack patterns of the specimens at ultimate loads. As shown in Figs. 3 and 4, all specimens underwent shear failure. In the case of the NP1F0 specimen, which is a conventional PSC member without steel fibers, only a diagonal crack appeared without any flexural crack. The load decreased suddenly at diagonal cracking, and shear failure occurred without a significant load increase compared to the diagonal cracking load. For the other specimens with steel fibers (SFRPSC beams), the load continued to increase without a degradation in stiffness when both flexural cracks and diagonal cracks occurred. The cracks developed to the bottom of the compression flange, and the SFRPSC beams showed shear failures which occurred immediately after reaching the maximum load. It is noted that part of the test data for the post-peak behavior of the HP2F1 specimen could not be measured because the testing equipment malfunctioned at the last point shown in Fig. 3. The diagonal cracking strength $\left(V_{c d r}\right)$, represented by triangular markers in Fig. 3, was significantly higher in all other specimens than in the NP1F0 specimen, which confirms that the steel fibers contributed to significant increases in the diagonal cracking loads of PSC members. In addition, the diagonal cracking strengths of specimens HP1F1, NP2F1, and HP2F1 were higher than those of the HPOF1 specimen because those specimens were prestressed. With respect to the shear strength $\left(V_{\max }\right)$, represented by the circular markers in Fig. 3, the specimens with steel fibers and a higher prestress level had higher shear strengths; the HP2F1 specimen thus showed the highest shear strength.

As shown in Fig. 4a, the NP1F0 specimen without steel fibers had a single diagonal crack, and most of the deformation was concentrated on the crack. In contrast, a large number of flexural and shear cracks occurred in the specimens with steel fibers as shown in Figs. $4 \mathrm{~b}$ to $4 \mathrm{e}$. It was also observed from the crack patterns of the NP2F1 and HP2F1 specimens that the inclination angles of the critical cracks were lower in the specimens with high prestress levels.

\subsection{Average Strain and Local Displacement}

In this study, the detailed measurements of average shear strain and local deformation behavior were obtained from the targets attached to the specimens. The average shear strain of the entire shear span $\left(\gamma_{x y}\right)$ was calculated from the displacement data from the four outermost targets attached to the surface of the web concrete; the results are shown in Fig. 5. Comparing the shear stress-strain relationships $\left(v_{u^{-}}\right.$ $\gamma_{x y}$ ) shown in Fig. 5 and the load-deflection curves shown in Fig. 3, it can be seen that shear stiffness rapidly decreased and shear strains increased significantly before reaching the maximum load. This obviously means that the members failed in shear after some components of the shear resistance mechanisms reached their limits. This pattern can also be observed in Fig. 6 which shows the contributions of shear deformation $\left(\delta_{s}\right)$ and flexural deformation $\left(\delta_{f}\right)$ to vertical deflection. Here, the vertical deflection caused by shear deformation $\left(\delta_{s}\right)$ was calculated by multiplying the shear strain shown in Fig. $5\left(\gamma_{x y}\right)$ by the shear span length $(a)$, while the vertical deflection caused by flexural deformation $\left(\delta_{f}\right)$ was calculated by subtracting the deflection caused by shear deformation $\left(\delta_{s}\right)$ from the total deflection $\left(\delta_{t o t}\right)$. The load-deflection relationships of the HP1F1 specimen shown in Fig. 6a demonstrate that the deflection caused by flexural 


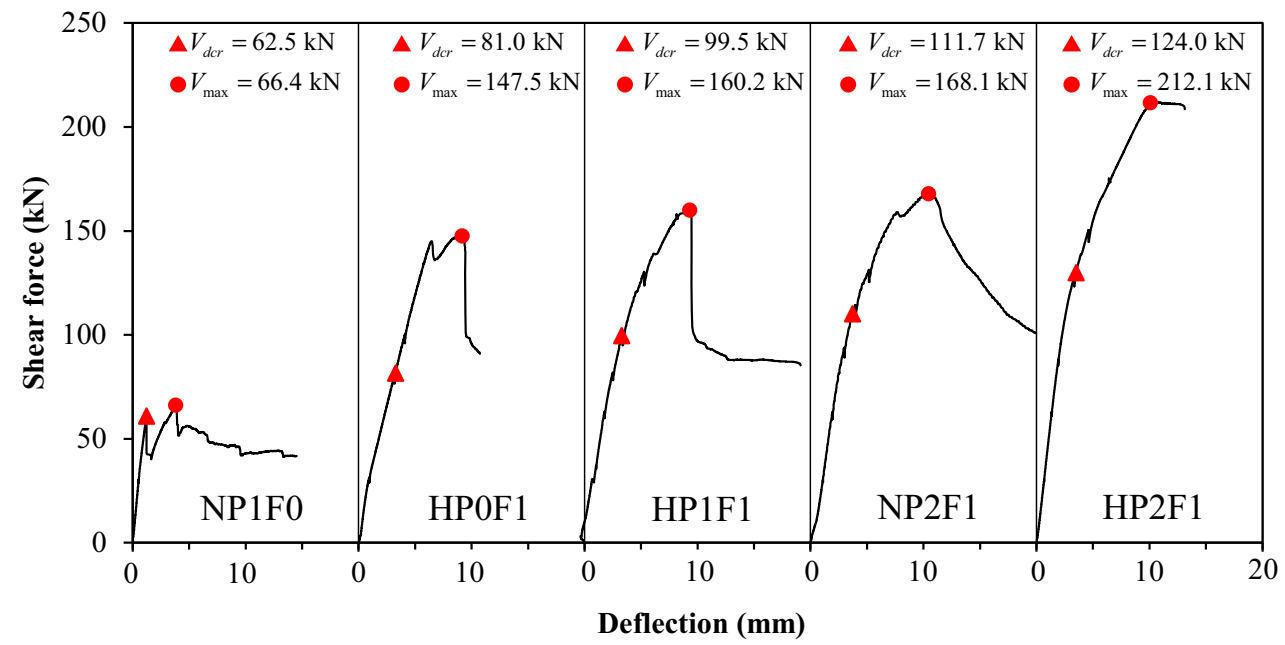

Fig. 3 Shear force-deflection curves.

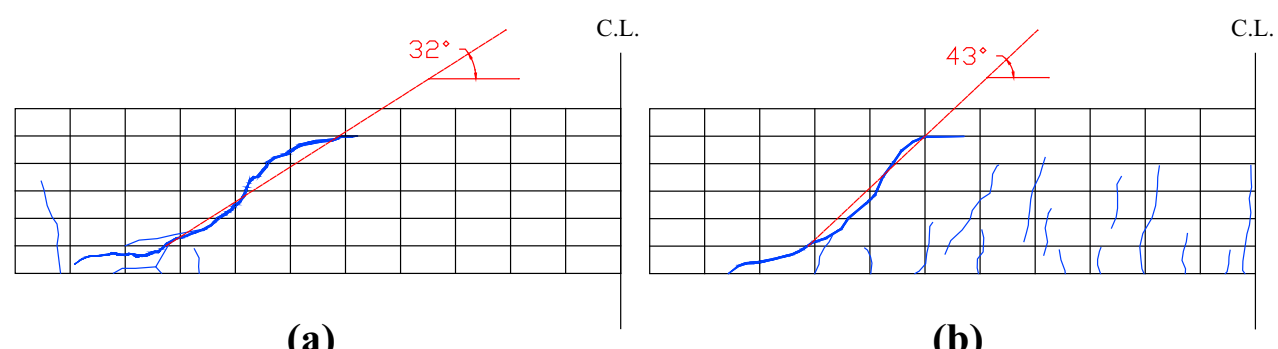

(a)

(b)

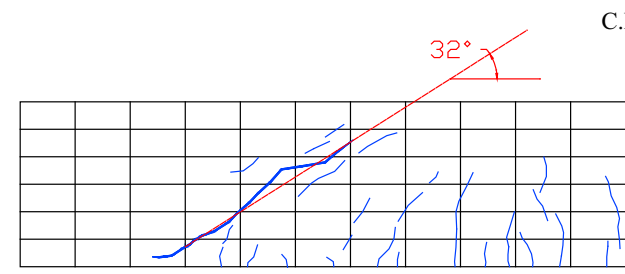

(c)

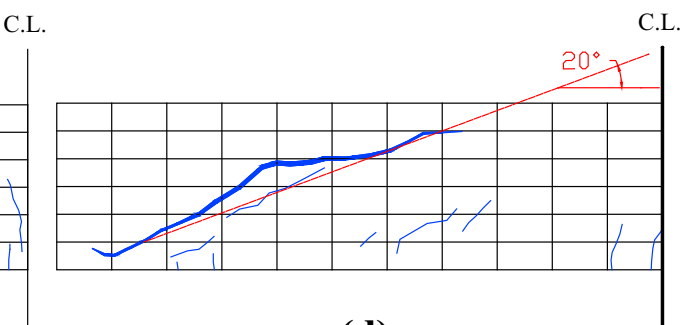

(d)

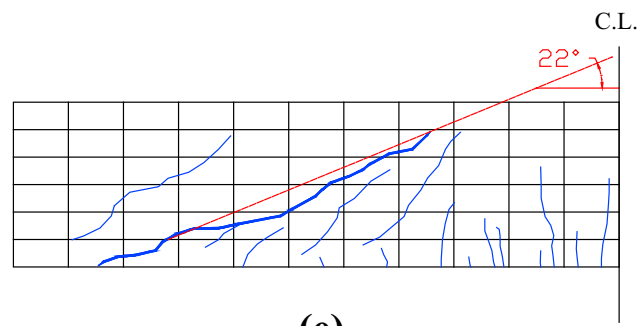

(e)

Fig. 4 Crack patterns of test specimens at ultimate loads. a NP1F0, b HP0F1, c HP1F1, d NP2F1, e HP2F1.

deformation increased linearly until reaching the failure load, and the vertical deflection of the member was dominated by flexural deformation until the load reached about $250 \mathrm{kN}$. After the appearance of the shear cracks, the vertical deflection caused by shear deformation increased significantly because of the rapid degradation of shear stiffness. The same pattern was observed in the HP2F1 specimen shown in Fig. 6b.

Using the displacement data obtained from four target sets attached close to the cracks, as shown in Fig. 7, the local deformation behavior near the shear cracks can be analyzed in more detail. As presented in Fig. 8, crack slips $\left(\Delta_{s}\right)$ and openings $\left(\Delta_{w}\right)$ were calculated as:

$$
\begin{aligned}
& \Delta_{s}=d x \cos \theta-d y \sin \theta \\
& \Delta_{w}=d x \sin \theta+d y \cos \theta
\end{aligned}
$$

where $d x$ and $d y$ are the displacements in the longitudinal direction and the vertical direction, respectively, and $\theta$ is 
the crack angle, for which this study used the average angles of the main critical crack in the web concrete (Figs. 4 and 7).

Figure 9 shows the crack opening and slip behavior of the test specimens at each target layer location presented in Fig. 7. It is noted that some targets (layer 1 of the HP1F1 specimen and layer 3 of the NP2F1 specimen) were detached during the experiment due to the surface spalling of concrete, and that such data could not be presented in Fig. 9. In addition, the target displacements were measured until the maximum load for the HP2F1 specimen and its crack opening and slip behavior is shown in Fig. 10. According to Fig. 9a, the NP1F0 specimen without steel fibers exhibited significantly larger crack openings $\left(\Delta_{w}\right)$ than crack slips $\left(\Delta_{S}\right)$, and the opening-to-slip ratio $\left(\Delta_{w} / \Delta_{S}\right)$ remained almost constant until the end of the experiment. Few changes were observed in the slope, even after reaching the maximum load, as represented by the vertical line in the figure. In addition, the magnitudes of the crack openings $\left(\Delta_{w}\right)$ and slips $\left(\Delta_{S}\right)$ in all layers were very similar,

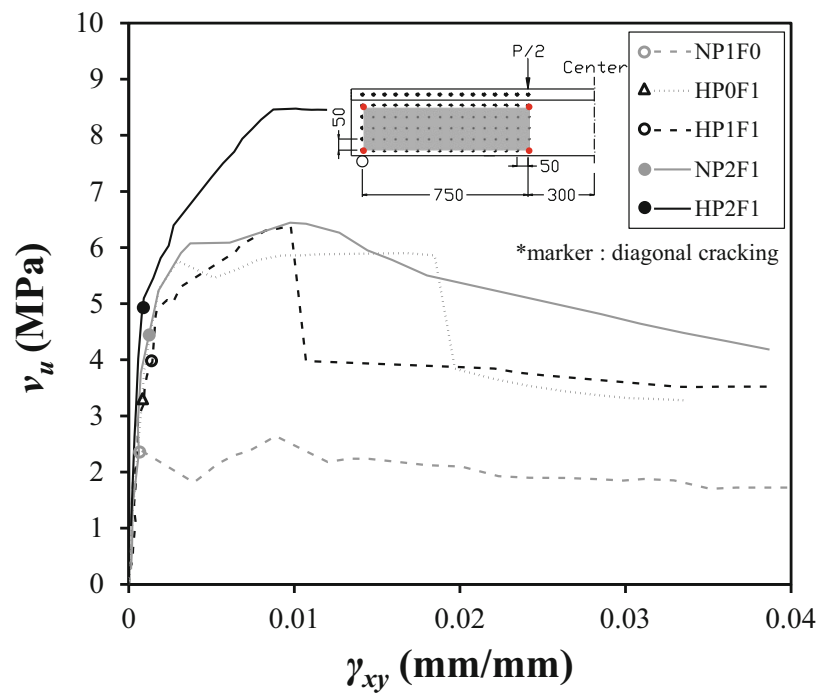

Fig. 5 Shear stress-strain relationships.

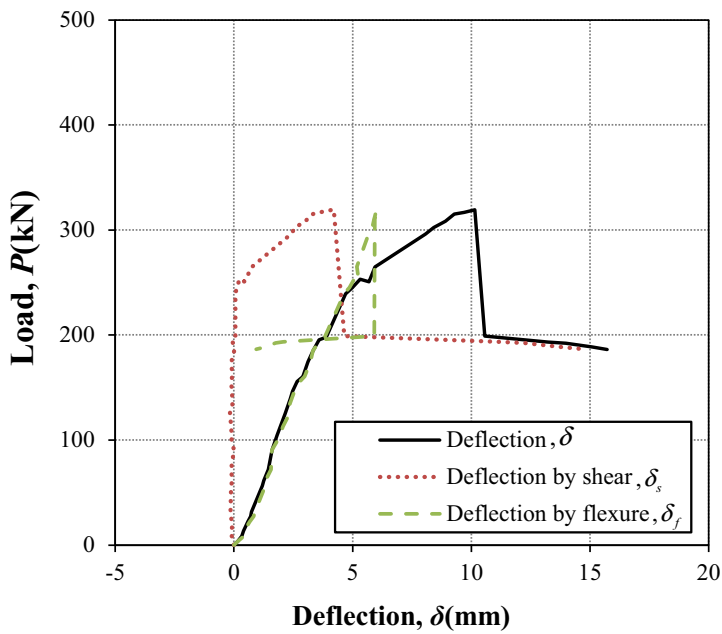

(a) and the crack openings $\left(\Delta_{w}\right)$ were larger than in the other test specimens. This is because the NP1F0 specimen had only one diagonal crack, and consequently all local deformations concentrated on this critical crack, while multiple diagonal or flexural cracks occurred in the other specimens with steel fibers. In the HPOF1 specimen that was not prestressed (Fig. 9b), the crack openings $\left(\Delta_{w}\right)$ were found to be slightly larger than the slips $\left(\Delta_{S}\right)$; the differences, however, were not significant. This means that the displacements occurred at about $45^{\circ}$ relative to the crack surface. As the crack angle of the HP0F1 specimen was approximately $43^{\circ}$ (Fig. 4), this result demonstrates that most displacements around the crack occurred in the vertical (y-axis) direction.

In the HP1F1 specimen shown in Fig. 9c, the differences between the crack openings and the slips were comparable to those of the NP1F0 specimen shown in Fig. 9a, but the magnitudes of the crack openings and the slips were smaller than in the NP1F0 specimen because of the resistances of steel fibers. The opening and slip displacements increased drastically when the shear strain increased by 0.03 , after which the opening and slip displacements of the HP1F1 specimen were similar to those of the NP1F0 specimen. This means that the resistance provided by steel fibers was significantly degraded due to the large shear strains after this

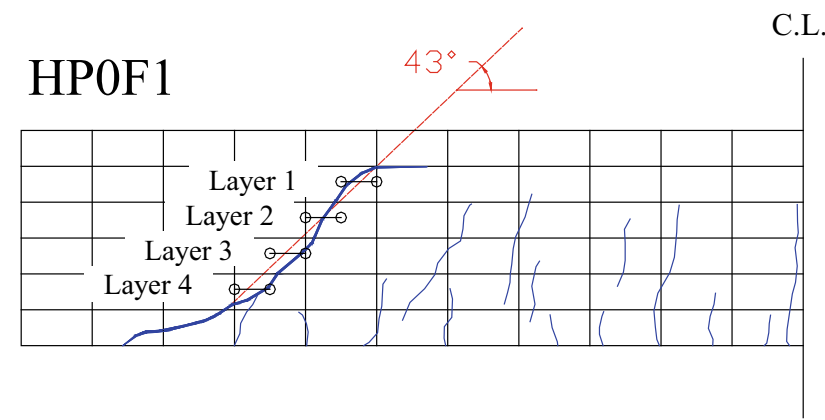

Fig. 7 Targets to measure local displacements near the diagonal crack.

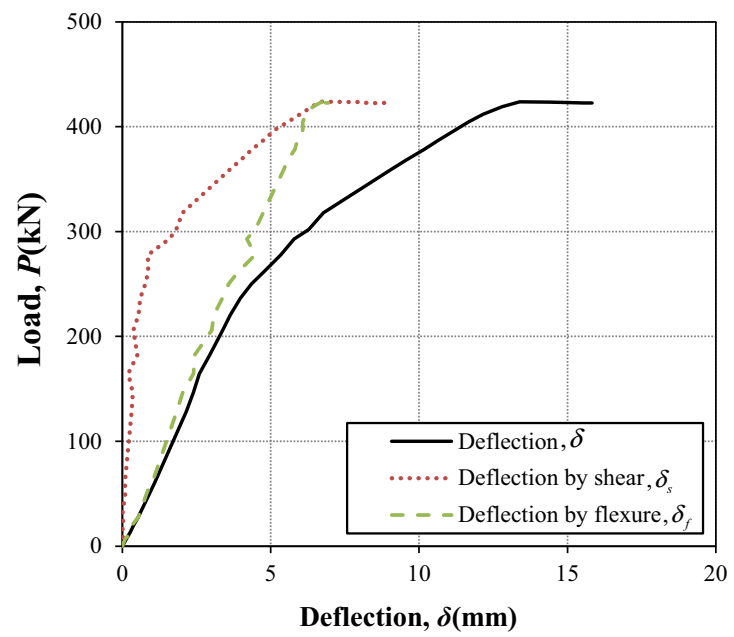

(b)

Fig. 6 Contribution of shear deformation on member deflection. a HP1F1, b HP2F1. 

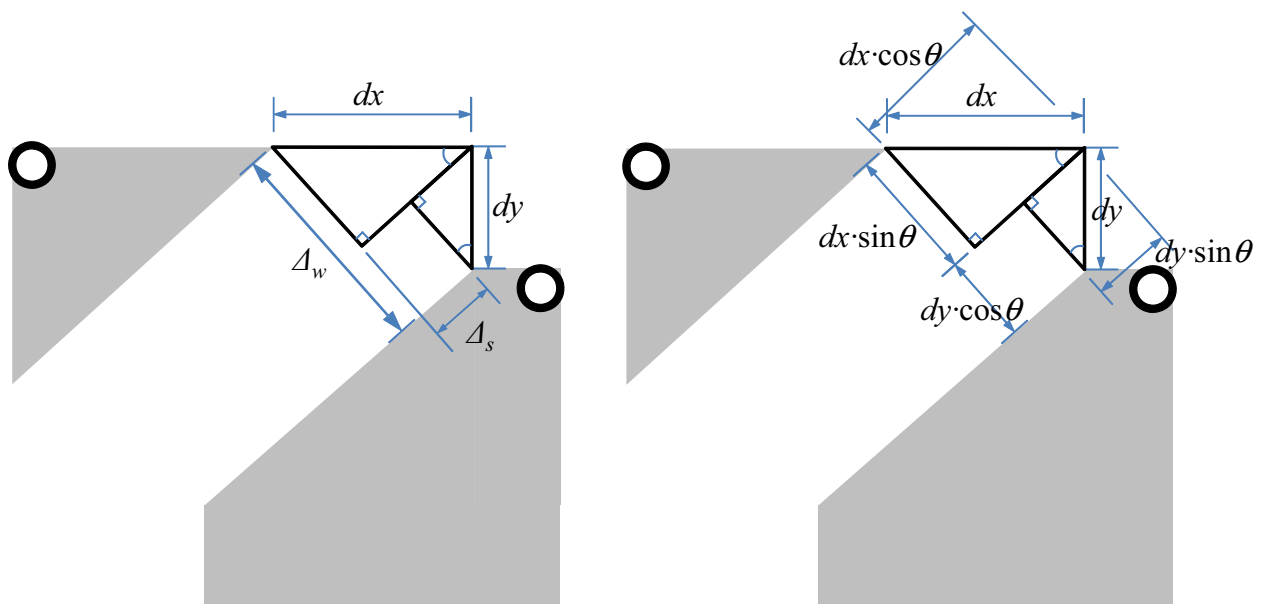

Fig. 8 Calculation of crack opening and slip.

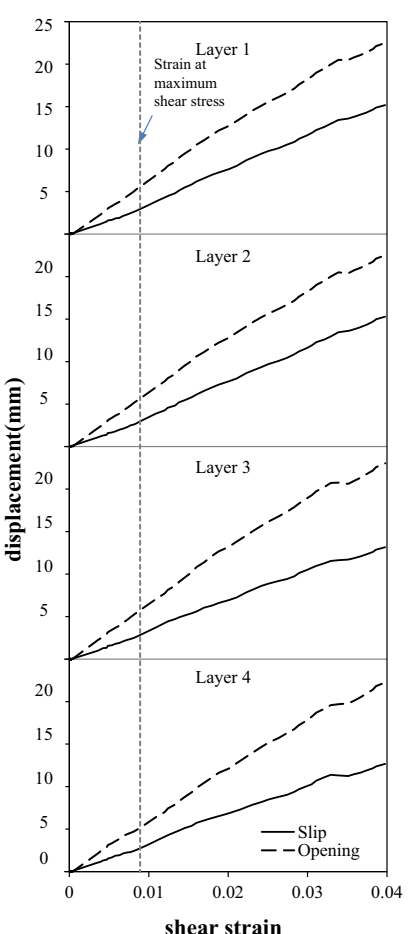

(a)

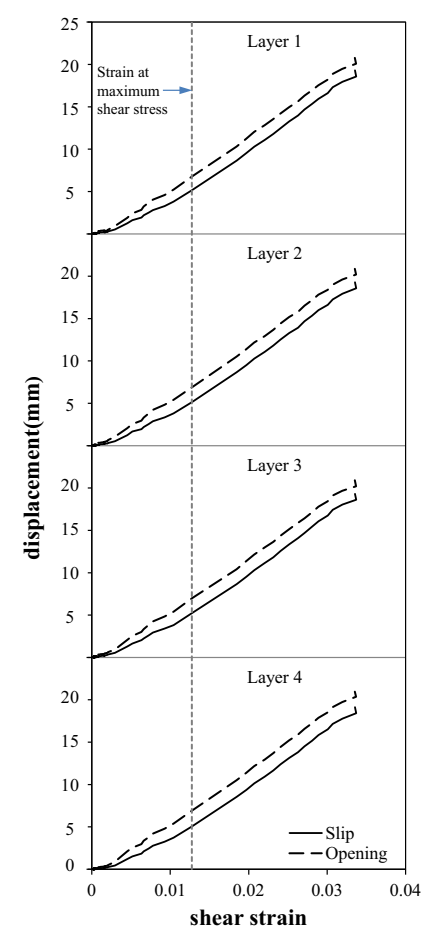

(b)

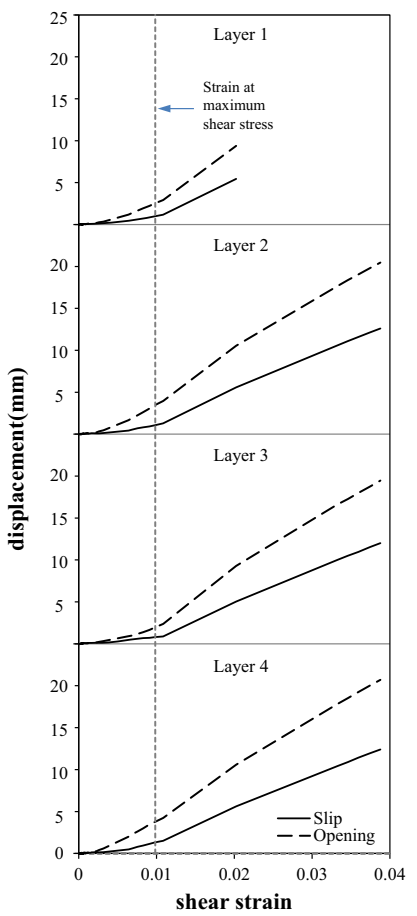

(c)

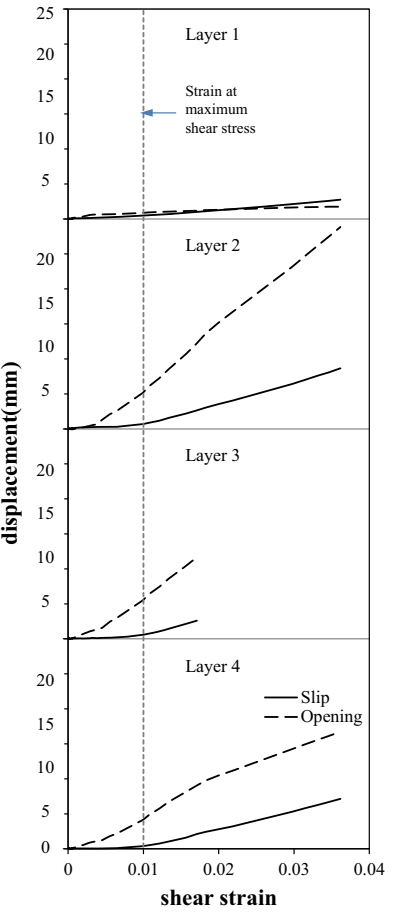

(d)

Fig. 9 Crack opening and slip of specimens. a NP1F0, b HP0F1, c HP1F1, d NP2F1.

point. The NP2F1 specimen shown in Fig. 9d exhibited significant differences between the crack openings and crack slips. The magnitude of crack openings was predominant, while the magnitude of slips was very low. Since the crack angle decreased as the prestress level increased, the slip displacements around the critical diagonal crack seemed to be controlled effectively in the NP2F1 specimen that had the highest prestress level among the specimens.

Figure 10 shows enlarged representations of the crack opening and slip displacements shown in Fig. 9 until the maximum loads, and Fig. 11 shows them against the shear stress. The NP1F0 specimen shown in Fig. 11a exhibited rapid increases in the crack opening and slip displacements right after a diagonal crack occurred. After that point, as shown in Fig. 10a, the opening and slip displacements increased almost linearly as the shear strain increased. As shown in Fig. 10b, the HPOF1 specimen exhibited a significant increase in opening and slip displacements after the strain reached approximately 0.0025 . The crack opening and slip displacements at the maximum load were larger than those of the NP1F0 specimen having no steel fiber because the maximum load of the HPOF1 specimen was much higher than that of the NP1F0 specimen. Furthermore, because the HP0F1 specimen was not prestressed, it exhibited larger opening and slip displacements than the HP1F1, NP2F1, and HP2F1 specimens that were prestressed. According to Fig. 10c, the HP1F1 specimen also exhibited an increase in opening and slip displacements at a shear strain of 0.0015 , where the shear stiffness decreased rapidly (Fig. 5). Compared to the NP1F0 specimen having no steel fibers, the 


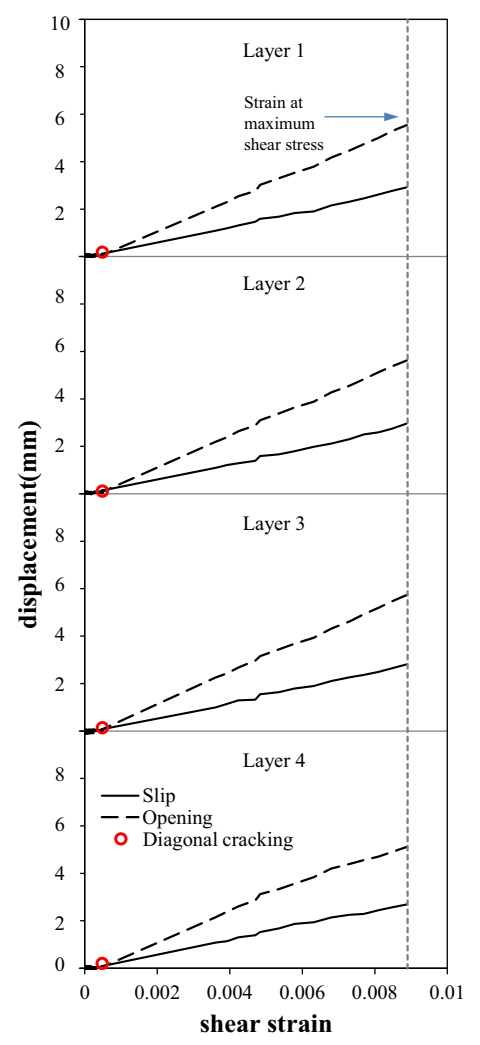

(a)

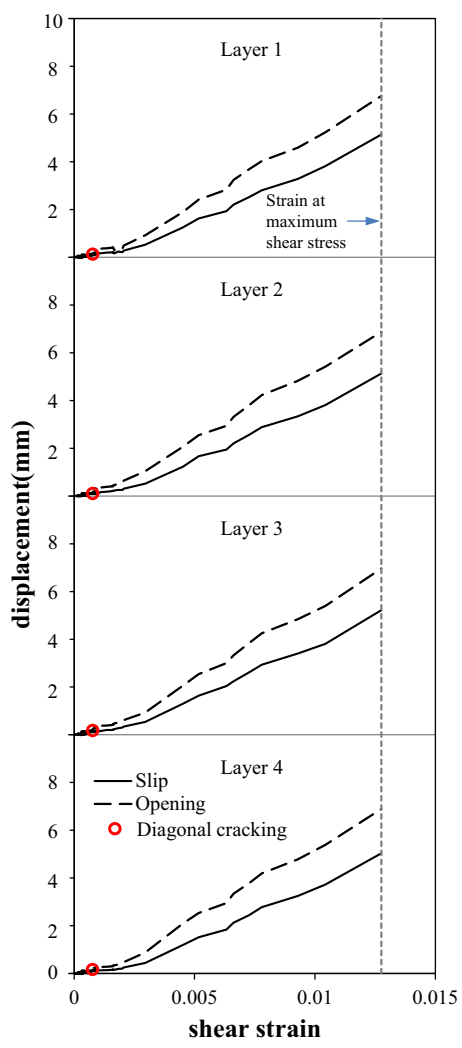

(b)

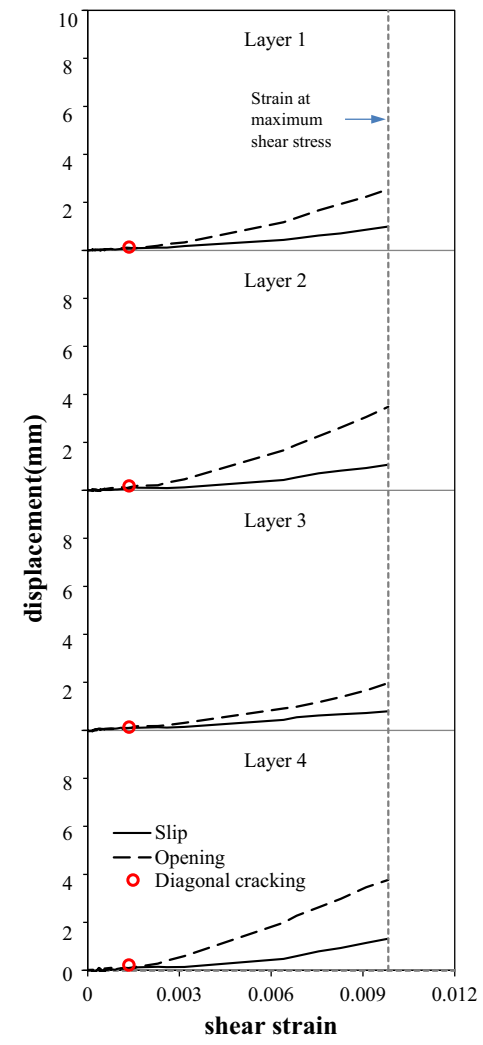

(c)

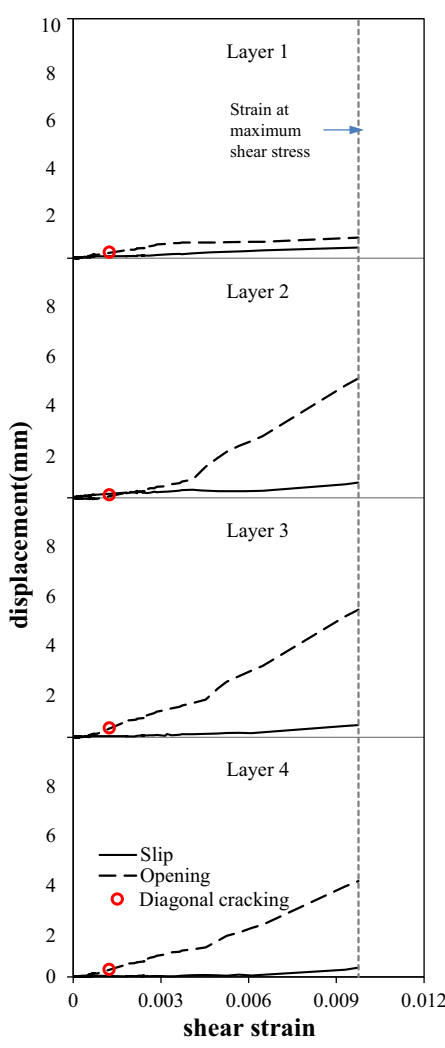

(d)

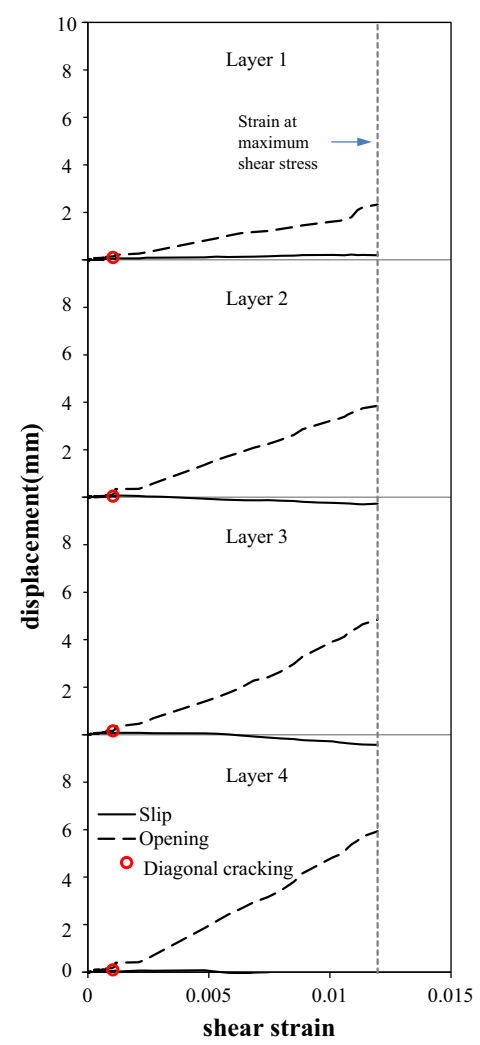

(e)

Fig. 10 Crack opening and slip of specimens enlarged to observe the parts before the line of maximum shear stress. a NP1F0, b HPOF1, c HP1F1, d NP2F1, e HP2F1.

HP1F1 specimen with steel fibers exhibited low magnitudes of openings and slips at a similar strain level by forming multiple shear cracks, which means that the steel fibers were very effective for crack control. According to Fig. 10d, the NP2F1 specimen exhibited an increase in the openings in layer 4 when the shear strain was approximately 0.001 , with 


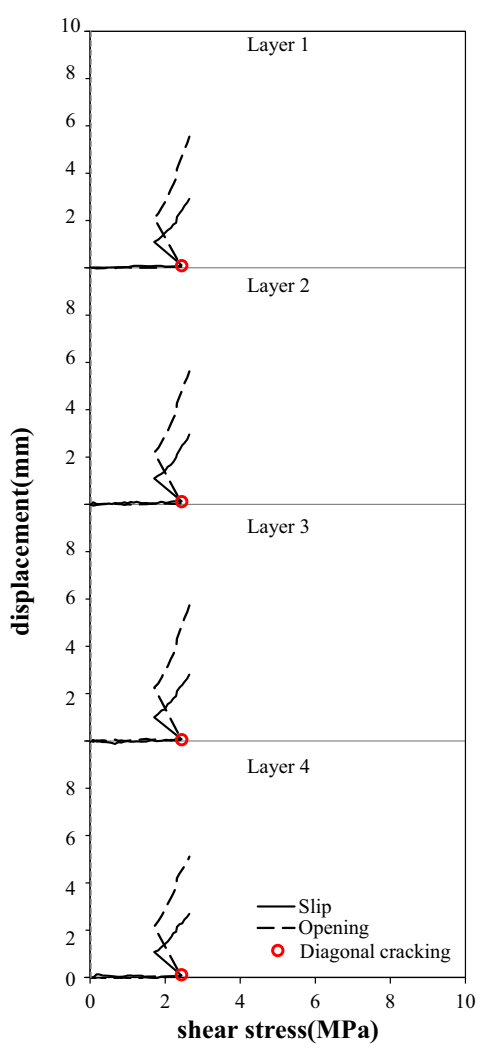

(a)

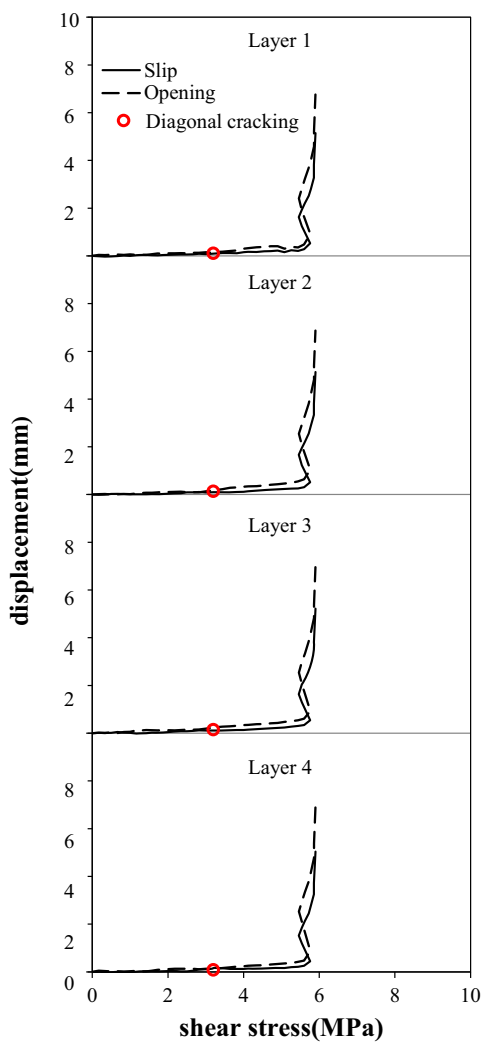

(b)

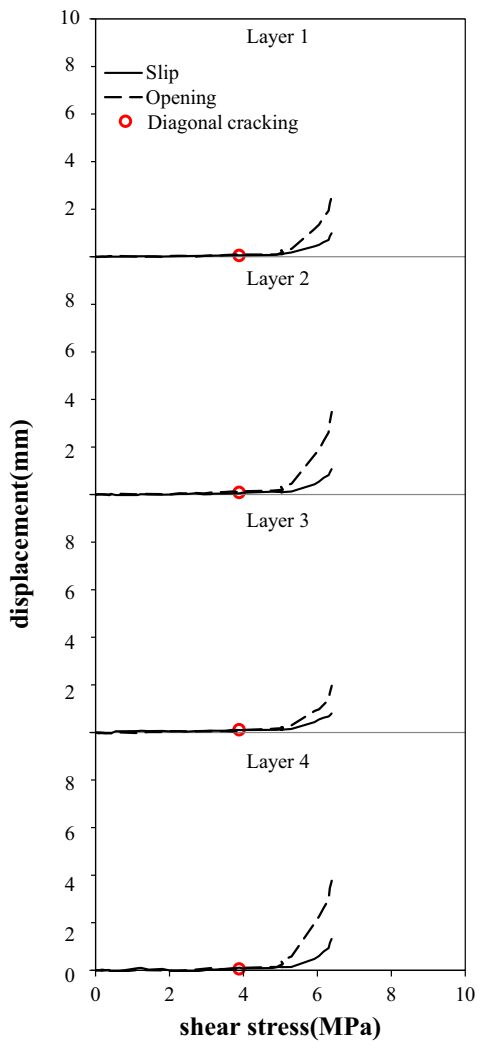

(c)

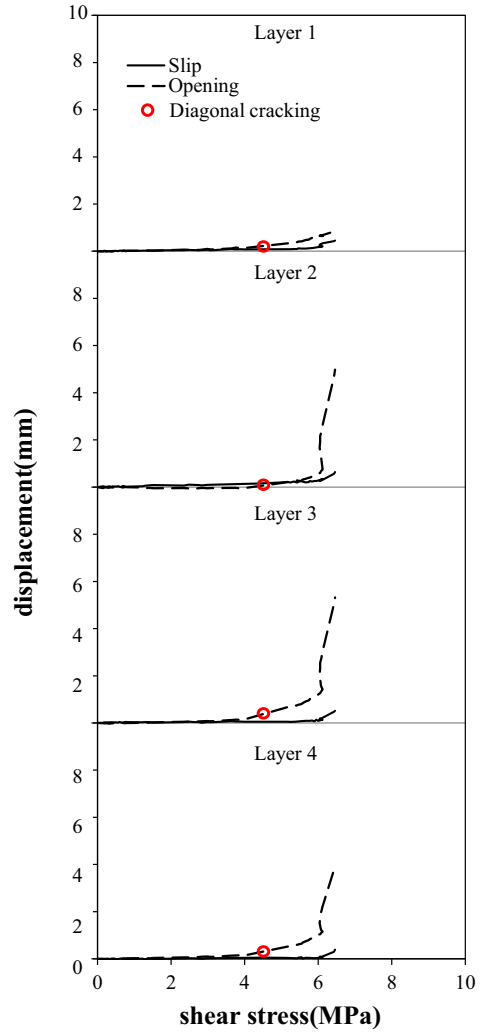

(d)

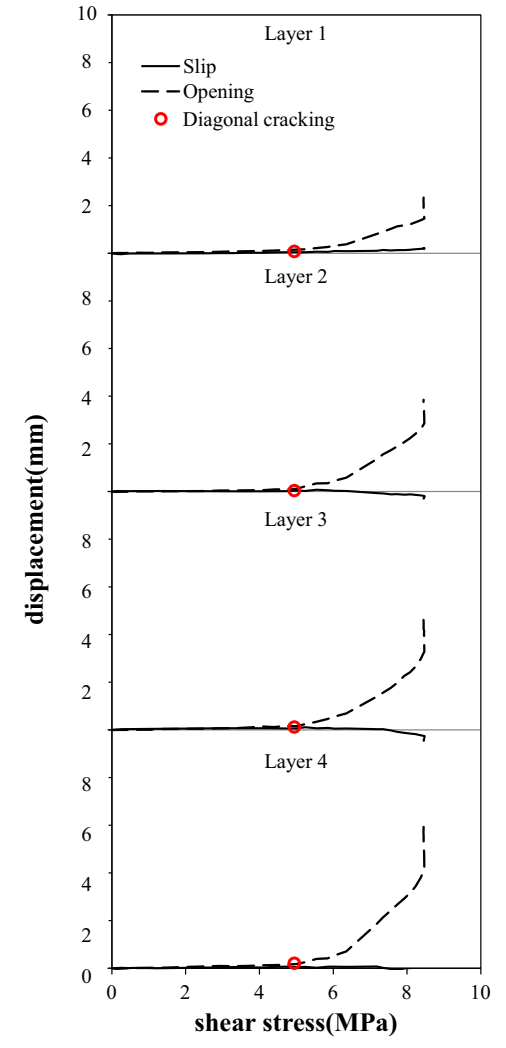

(e)

Fig. 11 Crack opening and slip of specimens at each layer according to shear stress. a NP1F0, b HP0F1, c HP1F1, d NP2F1, e HP2F1.

the openings occurring sequentially from layer 4 to layer 1 . In addition, layer 1 showed distinctively smaller displacements than the other layers along all the loading stages, because the neutral axis was still below layer 1 even until the maximum load reached. As shown in Figs. 10e and 11e, the HP2F1 specimen exhibited lower deformation than did the 


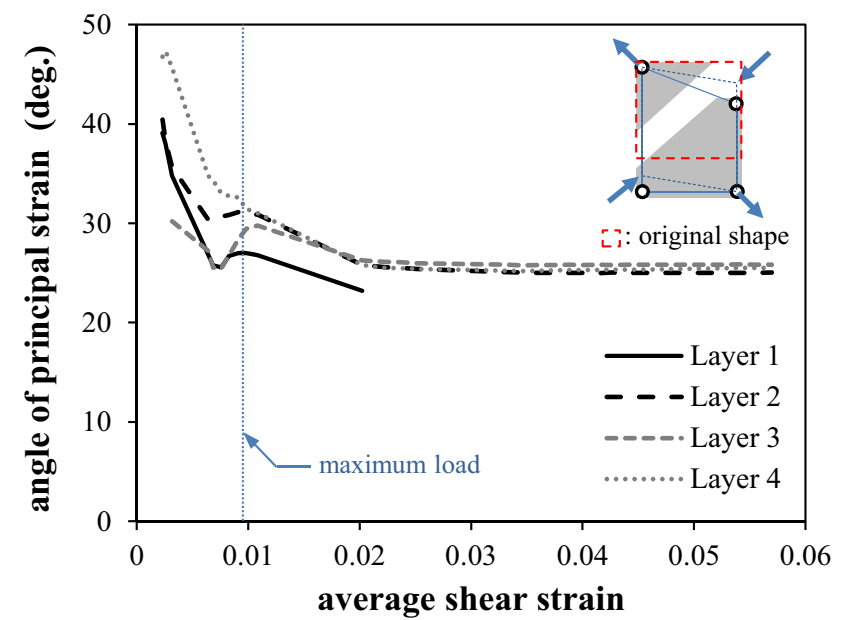

(a)

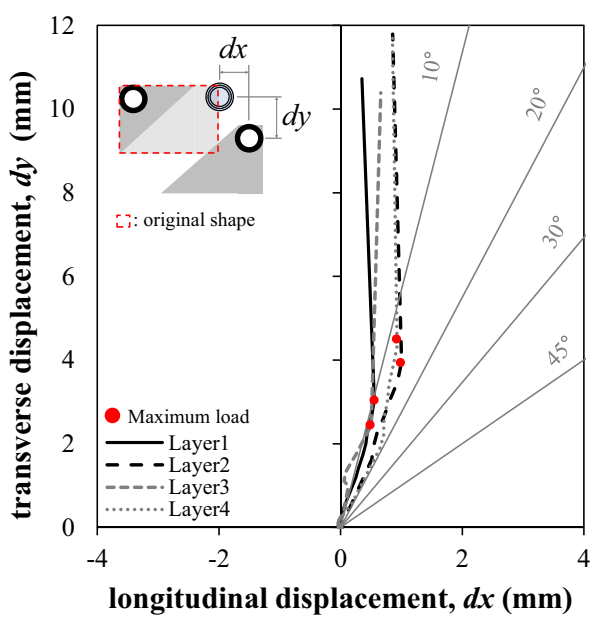

(b)

Fig. 12 Angle of average principal strains and local displacements of HP1F1 specimen. a Angle of average principal strain, b local displacement of each layer.

other specimens, which indicates that deformation can be very effectively controlled by prestress and fiber reinforcement.

Through the comparisons of the shear stress-strain behavior and the local opening and slip behavior between the NP1F0 specimen without steel fibers and the other specimens with steel fibers, the behavioral difference by the fiber reinforcement can be clearly observed. The shear strain of the NP1F0 specimen increased abruptly immediately after diagonal cracks appeared (Fig. 5). At this point when the shear strain was approximately 0.0005 (Figs. 10a and 11a), the slopes of the opening and slip also rapidly changed. Then, the opening and slip displacements increased at a constant rate without a significant change in the slope until the maximum load was reached. Because the tensile resistance of concrete in the direction perpendicular to the diagonal crack disappeared immediately after diagonal cracking, the angle of principal strain was changed, and consequently the slope of openings and slips was changed. Since then, however, there was no change in the resistance mechanisms, and little change therefore occurred in the slope of the openings and slips until after the maximum load was reached. On the other hand, the other specimens, which were reinforced with steel fibers (i.e., HP0F1, HP1F1, NP2F1, and HP2F1), showed no significant change in their shear stiffness when shear cracks occurred (Fig. 5). Instead, the shear strains increased after a significant increase in loads or even near their maximum loads. This can also be observed in Figs. $10 \mathrm{~b}$ to $10 \mathrm{e}$, in which the slopes of the opening and slip changed significantly in accordance with the rapid increase in shear strains a long time after diagonal cracking. The reason for no significant change in their shear stiffness as well as the slopes of slips and openings soon after diagonal cracking is that the steel fibers replaced the tensile resistance of the concrete that was lost at diagonal cracking. The steel fibers at the crack surface continuously resisted until they reached their bond strengths. Some fibers started to be pulled out at the crack opening of approximately $0.5-1.0 \mathrm{~mm}$ as shown in Figs. 10b to 10e, at which the slopes of the openings and slips changed significantly.

\subsection{Principal Directions of Average Strains and Local Displacements}

In concrete members subjected to shear force, the angle of principal strain $(\theta)$ is closely related to the contributions of shear resistance mechanisms, and it can be calculated as follows (Tadepalli et al. 2011; Vecchio and Collins 1986; Watanabe and Lee 1998):

$$
\theta=\frac{1}{2} \tan ^{-1}\left(\frac{\gamma_{x y}}{\varepsilon_{x}-\varepsilon_{y}}\right)
$$

where $\gamma_{x y}$ is the average shear strain, $\varepsilon_{x}$ is the longitudinal strain, and $\varepsilon_{y}$ is the vertical strain. In order to obtain the shear strain $\left(\gamma_{x y}\right)$ in Eq. (3), the average displacement and strains measured from any part of a member have been used in most experimental studies. Then, the shear strains $\left(\gamma_{x y}\right)$ are, in fact, dependent on the measuring ranges of the test specimen, and consequently the angles of the principal strains $(\theta)$ calculated from Eq. (3) differ. More importantly, the angles of the principal strains calculated from Eq. (3) differ from the directions of local displacements around the cracks that form discretely.

Figure $12 \mathrm{a}$ shows the angles of the principal compressive strains of the HP1F1 specimen calculated using Eq. (3) with the displacement data from four targets around the locations of the four layers shown in Fig. 7. The principal strain angles at each layer were initially between $30^{\circ}$ and $45^{\circ}$, and then decreased until stabilized at about $26^{\circ}$ with a shear strain of 0.02 . As shown in the drawing on the top right side of Fig. 12a, when the three targets attached to the concrete piece moved down only along the vertical direction (y-axis) due to cracking, the angle of principal compressive strain would not be calculated as zero, say $25^{\circ}-35^{\circ}$ or so, which is because the angle is calculated in an average manner. Figure $12 \mathrm{~b}$ shows the vertical displacement $(d y)$ with respect to 
the longitudinal displacement $(d x)$ obtained from the coordinates of two targets located at each layer and measured until immediately after the maximum load was reached. Across all the four layers, the longitudinal displacements $(d x)$ were $1 \mathrm{~mm}$ or smaller, during which the vertical displacements $(d y)$ increased up to about $10 \mathrm{~mm}$. This means that the vertical displacement $(d y)$ was dominant over the longitudinal displacement $(d x)$ in the specimen. In addition, the longitudinal displacement $(d x)$ occurred mostly before the maximum load, during which the displacement directions of the concrete around the crack $[\tan (d x / d y)]$ were between $10^{\circ}$ and $20^{\circ}$ relative to the vertical axis. After the maximum load was reached, only vertical displacements subsequently occurred, and the displacement directions of the concrete component below the crack were almost vertical, i.e., $0^{\circ}$ relative to the vertical axis, which significantly differed from the principal angles of the average strains (approximately $26^{\circ}$ ), as shown in Fig. 12a. For a proper interpretation of analysis results on shear behavior, such a difference should be carefully considered in both smeared crack models (Tan et al. 1996; Hwang et al. 2015; Vecchio and Collins 1986; Watanabe and Lee 1998) and discrete crack models (Oh and Kim 2004; Walraven 1981; Li et al. 1989).

\section{Conclusion}

In this study, shear tests were conducted on steel fiberreinforced and/or PSC members, and their localized behavior around the critical shear cracks was systematically measured by a non-contact image-based displacement measurement system. Based on the investigation conducted in this study, the following conclusions were drawn:

1. The test results showed that steel fibers and prestress were very effective in increasing the shear cracking strength and the ultimate shear strength of concrete beams.

2. In the specimens reinforced with steel fibers, the applied load increased continuously with little change in stiffness even after diagonal cracking, and the cracks were well controlled.

3. The shear stiffness of the specimens reinforced with steel fibers started to significantly decrease when the crack opening was about $0.5-1 \mathrm{~mm}$ because the fibers resisting at the crack surface started to reach their bond strengths.

4. The angle of average principal strain was calculated using the displacement data obtained from the targets attached to the surface of the concrete members. The angle was about $26^{\circ}$ under large shear strain. However, the actual deformation directions of the concrete elements around the cracks ultimately differed significantly. In particular, the actual deformations of concrete elements around the cracks occurred only in the vertical direction when the vertical displacement was more than $3 \mathrm{~mm}$.
5. The principal angles of average strains were found to differ considerably from the directions of local displacements around the cracks, and this difference therefore needs to be well understood when the shear behavior or the local behavior around the cracks are simulated by an analysis model.

\section{Acknowledgments}

This work was supported under the framework of international cooperation program managed by National Research Foundation of Korea (No. 2014K2A2A2000659).

\section{Open Access}

This article is distributed under the terms of the Creative Commons Attribution 4.0 International License (http://creativecommons.org/licenses/by/4.0/), which permits unrestricted use, distribution, and reproduction in any medium, provided you give appropriate credit to the original author(s) and the source, provide a link to the Creative Commons license, and indicate if changes were made.

\section{References}

Avendaño, A. R., \& Bayrak, O. (2011). Efficient shear reinforcement design limits for prestressed concrete beams. ACI Structural Journal, 108(6), 689-697.

Batson, G., Jenkins, E., \& Spatney, R. (1972). Steel fibers as shear reinforcement in beams. ACI Journal Proceedings, 69(10), 640-644.

Campione, G. (2014). Flexural and shear resistance of steel fiber-reinforced lightweight concrete beams. Journal of Structural Engineering, 140(4), 04013103.

Colajanni, P., Recupero, A., \& Spinella, N. (2012). Generalization of shear truss model to the case of SFRC beams with stirrups. Computers and Concrete, 9(3), 227-244.

Dinh, H. H., Parra-Montesinos, G. J., \& Wight, J. K. (2010). Shear behavior of steel fiber-reinforced concrete beams without stirrup reinforcement. ACI Structural Journal, 107(5), 597-606.

Furlan, S. Jr., \& Hanai, J. B. (1999). Prestressed fiber reinforced concrete beams with reduced ratios of shear reinforcement. Cement \& Concrete Composites, 21(3), 213-221.

Hwang, J.-H., Lee, D. H., Park, M.-K., Choi, S.-H., Kim, K. S., \& Pan, J. (2015). Shear performance assessment of steel fiber reinforced prestressed concrete members. Computers and Concrete, 16(6), 825-846.

Hawkins, N. M., \& Ghosh, S. K. (2006). Shear strength of hollow-core slabs. PCI Journal, 51(1), 110-115.

Islam, M. S., \& Alam, S. (2013). Principal component and multiple regression analysis for steel fiber reinforced concrete (SFRC) beams. International Journal of Concrete Structures and Materials, 7(4), 303-317. 
Karl, K. W., Lee, D. H., Hwang, J. H., Kim, K. S., \& Choi, I. S. (2011). Revision on material strength of steel fiber-reinforced concrete. International Journal of Concrete Structures and Materials, 5(2), 87-96.

Li, B., Maekawa, K., \& Okamura, H. (1989). Contact density model for stress transfer across cracks in concrete. Journal of the Faculty of Engineering, 40(1), 9-52.

Liu, H., Xiang, T., \& Zhao, R. (2009). Research on non-linear structural behaviors of prestressed concrete beams made of high strength and steel fiber reinforced concretes. Construction and Building Materials, 23(1), 85-95.

Narayanan, R., \& Darwish, Y. (1987). Shear in prestressed concrete beams containing steel fibres. The International Journal of Cement Composites and Lightweight Concrete, 9(2), 81-90.

Oh, B. H., \& Kim, K. S. (2004). Shear behavior of full-scale post-tensioned prestressed concrete bridge girders. $A C I$ Structural Journal, 101(2), 176-182.

Padmarajaiah, S. K., \& Ramaswamy, A. (2001). Behavior of fiber-reinforced prestressed and reinforced high-strength concrete beams subjected to shear. ACI Structural Journal, 98(5), 752-761.

Padmarajaiah, S. K., \& Ramaswamy, A. (2004). Flexural strength predictions of steel fiber reinforced high-strength concrete in fully-partially prestressed beam specimens. Cement \& Concrete Composites, 26(4), 275-290.
Spinella, N., Colajanni, P., \& La Mendola, L. (2012). Nonlinear analysis of beams reinforced in shear with stirrups and steel fibers. ACI Structural Journal, 109(1), 53-64.

Thomas, J., \& Ramaswamy, A. (2006). Shear strength of prestressed concrete T-beams with steel fibers over partial/full depth. ACI Structural Journal, 103(3), 427-435.

Tan, K. H., Paramasivam, P., \& Murugappan, K. (1996). Steel fibers as shear reinforcement in patially prestressed beams. ACI Structural Journal, 92(6), 643-651.

Tadepalli, P. R., Dhonde, H. B., Mo, Y. L., \& Hsu, T. T. (2015). Shear strength of prestressed steel fiber concrete I-beams. International Journal of Concrete Structures and Materials, 9(3), 267-281.

Tadepalli, P. R., Hoffman, N., Hsu, T. T. C., \& Mo, Y. L. (2011). Steel fiber replacement of mild steel in prestressed concrete beams. FHWA/TX-09/0-5255-2, Texas Department of Transportation, TX, USA, $177 \mathrm{p}$.

Vecchio, F. J., \& Collins, M. P. (1986). Modified compression field theory for reinforced concrete elements subjected to shear. ACI Journal Proceedings, 83(2), 219-231.

Watanabe, F., \& Lee, J. (1998). Theoretical prediction of shear strength and failure mode of reinforced concrete beas. $A C I$ Structural Journal, 95(6), 749-757.

Walraven, J. C. (1981). Fundamental analysis of aggregate interlock. Journal of Structural Engineering, 107(7), 2245-2270. 